\title{
um útero como máquina performática: UMA LEITURA DE UM ÚTERO É DOTAMANHO DE UM PUNHO NO MUNDO
}

Um útero as a performative machine: a reading of Um útero é do tamanho de um punho in the world

\section{Juliana de Assis Beraldo}

Resumo: Um útero é do tamanho de um punho (2012), de Angélica Freitas, apresenta lugarescomuns do discurso sobre mulheres usando diferentes procedimentos. O livro obteve uma recepção significativa e a partir dele se articularam leituras que focalizaram tanto aspectos poéticos como políticos. Este artigo possui como interesse central o mapeamento de alguns dos desdobramentos e modos de funcionamentos deste livro em diferentes esferas: desde o contexto de sua própria produção e inquietações primeiras, até a percepção de como estabelece relações com outras produções contemporâneas. A proposta é refletir sobre o livro como uma máquina performática, seguindo as discussões de Aguilar e Cámara (2017). Trata-se de uma abordagem que pretende analisar os mais diversos signos que compõem o campo dos poemas permitindo pôr em discussão noções de literário, estético e político. Assim, este trabalho deseja impulsionar estudos sobre as políticas da poesia e da crítica, entendendo a literatura como campo expandido (KRAUSS, 1979) e buscando possibilidades e experimentações no método de crítica por meio de uma experiência de desierarquização dos signos. Portanto, incentivase a refletir sobre a forma com que os poemas circulam e impactam a sociedade promovendo outras configurações políticas.

Palavras-chave: Angélica Freitas; Máquina performática; Literatura; Mundo; Mulher; Poesia contemporânea brasileira.

Abstract: Um útero é do tamanho de um punho (2012), by Angélica Freitas, presents discursive commonplaces about women using different procedures. The book has obtained a significative reception and became a starting point of relevant readings that focused both poetic and political aspects. This paper has as central interest the mapping of some of the unfolding and ways of functioning of the book in different spheres: from the context of its own production and primary concerns, to the perception of how it establishes relations with other contemporary works. The proposal is to reflect upon the book as a performative machine, following the discussions by Aguilar and Cámara (2017). It is about an approach that intends to analyze the diverse signs that may compose the field of the poems permitting to raise discussions on the notions of literary,

1 Graduada em Letras Português-Inglês pela Universidade Federal do Rio de Janeiro, é mestranda no Programa de Pós-Graduação em Ciência da Literatura (UFRJ). E-mail: julianaassis8oo@hotmail.com 
aesthetic and political. This way, this work aims to foster studies about poetic and critical politics, comprehending literature as an expanded field (KRAUSS, 1979) and seeking possibilities and experiments in the critical method through an experience of signs dehierarchization. Therefore, it encourages to reflect about the way poems circulate and impact society promoting other political configurations.

Keywords: Angélica Freitas; Performative machine; Literature; world; Women; Contemporary Brazilian poetry.

Em entrevista para o canal do YouTube Estratégias Narrativas, desenvolvido por Laura Cohen, Angélica Freitas comenta seus livros de poesia. A poeta gaúcha menciona que seu segundo lançamento, Um útero é do tamanho de um punho (2012), teria surgido a partir de uma inquietação. Segundo ela, naquele momento, queria escrever sobre algo que lhe "dissesse respeito" e complementa: "eu não achava na literatura feita por mulheres no Brasil poemas escritos sobre o que é ser mulher". E é assim que Freitas costuma definir seu último livro de poemas: "um livro sobre mulheres". Em uma resenha para o Suplemento Pernambuco publicada em 2017, Adelaide Ivánova, também poeta, jornalista e tradutora, escreve sobre o livro de Freitas a partir das primeiras conversas que tiveram. Em algum momento, Adelaide pergunta sobre a relação do Jornalismo, curso no qual Angélica é formada, com a escrita de poesia. "Ah, Adelaide, eu entendo poesia como investigação", Freitas responde. A maneira com que Angélica Freitas conceitua poesia parece apontar para uma relação entre literatura e mundo. Ou melhor, para uma escrita que se entende como incisiva nas dinâmicas literárias e políticas, capaz de investigá-las, de mobilizá-las. Mas quais são, então, os vínculos entre literatura e mundo? Interessa, aqui, observar os desdobramentos desse livro com o/no/para o mundo, tanto nos impactos posteriores à publicação como nos procedimentos que a poeta lança mão para a investigação que empreende.

Ao propor a análise deste livro em sua relação com os modos de produção de texto e de mundo, parto da perspectiva de conceber Um útero é do tamanho de um punho (2012) em um campo expandido. Ou seja, desde sua fase de produção e inquietações primárias e nas relações que estabelece no mundo ou de como cria mundo. Uma tarefa que objetiva romper, em alguma medida, com a noção de texto como apenas grafismo para considerá-lo em sua diversidade de signos, como um espaço que não cessa de se expandir. 
Essa concepção é retomada por Aguilar e Cámara (2017), desdobrando a discussão de Rosalind Krauss (1979) em seu artigo "A escultura no campo expandido". Os autores propõem reconsiderar os limites entre texto e mundo ou entre dentro e fora do texto. Uma discussão que se aproxima do que diriam Deleuze e Guattari: "o livro não é a imagem do mundo segundo uma crença enraizada. Ele faz rizoma com o mundo (...)" (DELEUZE; GUATTARI, 1996, p. 28), sugerindo a saída de uma noção binária de análise.

Nessa mesma linha, Aguilar e Cámara defendem, em A máquina performática, uma concepção de que não há dentro ou fora de um texto, mas um dispositivo, um campo ou um "espaço que põe os signos em relação sem distinção do domínio ao qual pertencem" (AGUILAR; CÁMARA, 2017, p. 8). Ou seja, propõe-se uma concepção de texto e de olhar para o texto considerando-o como uma rede de signos sem uma hierarquia. Uma máquina performática que está sempre tecendo redes e criando cenas. Como e por meio de que estratégias certas redes literárias, estéticas e políticas são tecidas? Quem as tece? Quais os impactos dessas redes? Ou antes, pode um texto criar redes ou cenas? Enquanto Adelaide Ivánova comenta em sua resenha, "Como age, pensa e o que é uma mulher?", os modos de produção do livro de Angélica Freitas, esta pode nos servir como um vestígio de algumas redes as quais esse texto pode esboçar.

\section{a "googlagem": um modo de investiqacão}

A partir do desejo de investigação sobre o que é ser mulher, conforme descrito tanto na entrevista como na resenha, Angélica escreveu três poemas que ganharam uma seção própria. Como metodologia para a investigação, a poeta usou a ferramenta, provavelmente, mais difundida e comum das últimas décadas: o Google. Em um texto para a revista E-lyra, Freitas descreve o procedimento ao qual chamou de googlagem, juntando "google" e "colagem":

Enquanto escrevia meu segundo livro de poemas ("Um útero é do tamanho de um punho", editora Cosac Naify, 2012), que tinha a mulher como tema principal, decidi buscar na internet textos sobre o corpo feminino. Queria saber como eram escritos, com que palavras, com que autoridade. Um dia coloquei no Google "A mulher é" - vai que obtivesse alguma resposta interessante. Fui copiando e 
colando os resultados para talvez montar um poema mais tarde. Ao ler o material que havia juntado, percebi que nem fazia falta dar-lhe uma "ordem". Não havia como ficar menos ou mais absurdo do que aquilo. Permaneceu inédito. Foi um teste, o embrião da série "Três poemas com o auxílio do Google" ("A mulher vai", "A mulher quer", "A mulher pensa"), que acabou sendo publicada no livro (FREITAS, 2016, p. 354).

No caso da seção "3 poemas com auxílio do google", diferente do teste que Angélica diz ter feito com "A mulher é", é possível suspeitar de algum tipo de manuseio dos resultados por parte da autora devido à narratividade que o poema apresenta. Em "A mulher quer", por exemplo, parece haver uma sequenciação de desejos, desde "a mulher quer ser amada" até o trágico "a mulher quer se suicidar".

\section{a mulher quer}

a mulher quer ser amada

a mulher quer um cara rico

a mulher quer conquistar um homem

a mulher quer um homem

a mulher quer sexo

a mulher quer tanto sexo quanto o homem

a mulher quer que a preparação para o sexo aconteça lentamente

a mulher quer ser possuída

a mulher quer um macho que a lidere

a mulher quer casar

a mulher quer que o marido seja seu companheiro

a mulher quer um cavalheiro que cuide dela

a mulher quer amar os filhos, o homem e o lar

a mulher quer conversar pra discutir a relação

a mulher quer conversa e o botafogo quer ganhar do flamengo

a mulher quer apenas que você escute

a mulher quer algo mais do que isso, quer amor, carinho

a mulher quer segurança

a mulher quer mexer no seu e-mail

a mulher quer ter estabilidade

a mulher quer nextel 


\begin{abstract}
a mulher quer ter um cartão de crédito
a mulher quer tudo

a mulher quer ser valorizada e respeitada

a mulher quer se separar

a mulher quer ganhar, decidir e consumir mais

a mulher quer se suicidar
\end{abstract}

(FREITAS, 2012, p. 72).

A sentença "a mulher quer" é repetida verso a verso, como uma espécie de listagem de discursos comuns sobre o que seriam os desejos da mulher. Com o predomínio de desejos ligados ao consumo e a um erotismo heterossexual, a exibição desses lugares-comuns não dá a ver de quem é a voz ou a autoridade por trás dos discursos, ou seja, quem é que afirma o que a mulher quer. Tratase de uma voz anônima e generalizada que se dirige a uma "mulher" universal. Embora se tente preencher o desejo da mulher em todos os versos é como se, ao final, ele ficasse em suspensão, colocando em questão a veracidade dos versos anteriores. O desejo da mulher assim como a própria mulher são signos vazios: apesar da tentativa de preencher, são esvaziados pela lógica do poema, tanto pela repetição como pelo último verso.

Outro ponto é que a leitura do poema ao mesmo tempo que expõe discursos machistas acaba por produzir humor. Em primeiro lugar, o poema pode ser lido em uma narrativa da construção da vida heteronormativa de uma mulher que implicaria: 1- querer um homem ("a mulher quer ser amada", "a mulher quer um homem"); 2- ser esposa e infeliz ("a mulher quer amar os filhos, o homem e o lar", "a mulher quer apenas que você escute"); 3- se separar para ser independente; 4- se suicidar. Esses estágios que definiriam o ciclo heterossexual patriarcal ao qual uma mulher seria parte parecem pressupor uma falta de escapatória perante a lógica desigual, em termos de gênero, da sociedade. No entanto, a exploração dessa fatalidade do desejo da mulher (heterossexual) não parece se exibir em tom dramático. Pelo contrário, o último verso indica um tipo de ironia com o estereótipo e a expectativa de uma sociedade machista que preveria um padrão estável dos desejos das mulheres. E, assim, brinca com a própria insatisfação das mulheres, que preferem a morte.

Em segundo lugar, muito além de uma risada cômica, ri-se pelo estranhamento perante a exposição do absurdo das falas que já foram 
naturalizadas no cotidiano. Ou seja, o humor, neste aspecto, parece agir como o lugar por meio do qual se dá a crítica. É justamente através desse efeito de listagem que se tornam perceptíveis os enunciados machistas aos quais são articulados o que se pensa serem os desejos das mulheres. Deste modo, o poema nos convida a rir deste conjunto de significados patriarcais, dessa sexualidade passiva e bem definida ("a mulher quer ser possuída/ a mulher quer um macho que a lidere") sob os quais a simbologia de um corpo feminino está inscrito.

Em termos da relação de construção do feminino e do Google, é com o uso da ferramenta de busca virtual à procura de, como escreve Angélica, "alguma resposta interessante" que se manifesta o funcionamento da Web como uma rede discursiva, tecnológica e informacional. No artigo "The anatomy of a large-scale hypertextual Web search engine", publicado em 1998, Brin e Page, os fundadores do Google, apresentam o protótipo de um mecanismo de busca que se tornaria, segundo diversas pesquisas, o website mais visitado do mundo. O objetivo do desenvolvimento do Google frente a outros sites de pesquisa, como o Yahoo, conforme frisam seus desenvolvedores, era de aprimorar a qualidade dos resultados. Por meio de estratégias de indexação de páginas com hipertextos e o que chamam de PageRank, os autores simulam o comportamento de um usuário para observar a dinâmica de acesso às páginas. Brin e Page tomam como modelo o usuário aleatório (random surfer), o tipo de usuário entediado. Descrevem, da seguinte forma:

O PageRank pode ser pensado como um modelo do comportamento do usuário. Assumimos que haja um "usuário aleatório" (random surfer) a quem é dada uma página da Web aleatória e que clica continuamente em links nunca apertando "voltar", mas eventualmente, ficando entediado e começando novamente em outra página aleatória. A probabilidade do usuário aleatório visitar uma página é seu PageRank (BRIN; PAGE, 1998, p. 110, tradução minha).

Essa estratégia do PageRank nada mais faz do que explicitar o grau de indexação ao qual as páginas estão interligadas, classificando-as como mais ou menos confiáveis. Para os pesquisadores, ela garantiria que os melhores resultados, ou seja, resultados provenientes de páginas de maior credibilidade, sejam selecionados. Nesse sentido, a noção de bons resultados 
estaria ligada aos discursos que estabeleçam redes - as mais complexas possíveis - entre si. Embora o funcionamento do Google já tenha sido alterado desde sua criação, o modelo de eficiência, segundo a anatomia descrita pelos criadores, parece estar pautado em uma proposta de reprodução mecânica de um dialogismo² que toma como base um usuário tal qual Angélica Freitas na googlagem. Na pesquisa "o que é mulher" ou "o que a mulher quer", Freitas se configura como uma usuária aleatória buscando exatamente pelos nós da rede discursiva que define os "melhores resultados" para a categoria "mulher". Aleatória no sentido de não estar buscando um resultado específico, mas ocupando de forma nômade, mapeando o que está colocado.

Assim, em vez de manter o uso tradicional da ferramenta da busca, a poeta parte de um lugar de usuário aleatório - lugar inútil, que não visa chegar a algum resultado eficiente - e passa a desempenhar um trabalho cirúrgico de manuseio do discurso. Dá-se, desta maneira, a feitura do poema a partir de um novo uso para o Google. Essa subversão dos usos refuncionaliza tanto os modos de produção tradicionalmente esperados da poesia quanto a expectativa de uso do site, evidenciando que não se trata de uma ferramenta acriteriosa. Mas, pelo contrário, uma plataforma que expõe e arquiva lugares-comuns e enunciações que agenciam a construção do signo "mulher". Demonstra-se, neste gesto, o próprio procedimento de construção, de armamento do corpo e do gênero/sexo, suas dimensões discursivas e, sobretudo, tecnológicas.

Fazer corpo a partir do Google ou pensar a mulher como uma construção, para nos referirmos a outro poema de Freitas, recoloca questões importantes acerca de natureza e tecnologia. O teórico transfeminista Paul Beatriz Preciado percebe a estrutura gênero/sexo como um dispositivo tecnológico - protético, hormonal, farmacêutico e pornográfico - e enfatiza, com isso, a dissolução de dualismos natureza versus tecnologia. Preciado (2014) menciona que a teórica Donna Haraway já defendia que o próprio conceito de humanidade "depende da noção de tecnologia". Haraway demonstra que o "(hu)mano/hu-man" se define, antes de mais nada, como um "animal que utiliza instrumentos", por oposição aos primatas e às mulheres" (HARAWAY,

2 Para Bakhtin, a linguagem é de natureza dialógica, ou seja, os enunciados estão sempre ligados entre si em cadeia. "Cada enunciado isolado é um elo na cadeia da comunicação discursiva." (BAKHTIN, 1979, p. 299). 
1998, p. 9 apud PRECIADO, 2014, p. 148).

O que nos cabe pensar com a googlagem é a possibilidade de observarmos a instância tecnológica e discursiva de construção e reverberação de estereótipos de gênero na Internet, esta funcionando como tecnologia de construção (e reafirmação da norma) do que se entende socialmente por feminino. Ao mesmo tempo em que se obtêm definições de gênero, desejo e corpo com os resultados do Google, compreende-se uma dimensão performativa da linguagem ${ }^{3}$ ou um potencial da linguagem de agir e construir significados. Como afirma Paul B. Preciado,

o sistema sexo/gênero é um sistema de escritura. O corpo é um texto socialmente construído, um arquivo orgânico da história da humanidade como história da produção-reprodução sexual, na qual certos códigos se naturalizam, outros ficam elípticos e outros são sistematicamente eliminados ou riscados. A (hetero) sexualidade, longe de surgir espontaneamente de cada corpo recém-nascido, deve se reinscrever ou se reinstruir através de operações constantes de repetição e recitação dos códigos (masculino e feminino) socialmente investidos como naturais (PRECIADO, 2014, p. 26).

Essa escritura é trabalhada por um regime político heterossexual descrito por Preciado como "máquina de produção ontológica que funciona mediante a invocação performática do sujeito como corpo sexuado" (PRECIADO, 2014, p. 28). Em outras palavras, trata-se de uma máquina produtora do que a mulher é, desse ser socialmente esperado. São, portanto, tecnologias de produção de diferenciação de sexo/gênero em masculino/feminino a fim de manter certas dinâmicas de poder. Como observamos, os clichês explorados em "A mulher quer" exibem textualmente a silhueta padrão do sexo-gênerodesejo designados como feminino e, ainda mais, o lugar do Google como um "arquivo orgânico" que preserva esses discursos e que, de diferentes

3 A ideia da linguagem como performance aqui se remete aos estudos da teoria dos atos da fala de J. L. Austin. Austin entende que a linguagem é performativa no sentido de que o ato da fala é compreendido como uma ação. Na apresentação da edição brasileira de Quando dizer é fazer: palavras e ação (1990), de Austin, Danilo Marcondes Filho resume que, para Austin, "a linguagem é uma prática social concreta e como tal deve ser analisada. Não há mais separação radical entre "linguagem" e "mundo", porque o que consideramos a "realidade" é constituído exatamente pela linguagem que adquirimos e empregamos" (1990, p. 10). 
maneiras, reitera enunciações hegemônicas4.

Junto com a possibilidade de observar como o sexo/gênero é citado e reconstruído discursivamente e, logo, corporalmente, com a Internet a partir da googlagem, Freitas lança o debate da noção de poesia e escrita. Se o que se chama de poema, nesse caso, é uma investigação do (e a partir do) Google como uma espécie de arquivo de gênero, o que essa proposta tem a nos dizer sobre a concepção de poesia ou poema? Usar o Google para fazer poesia permite deslocar a noção de "literário" de sua determinação grafocêntrica usual. Isto é, ao ler os "3 poemas com auxílio do google" é necessário considerar não só o grafismo, isto é, as palavras no papel, mas, refletir necessariamente sobre o procedimento de construção do próprio poema assim como dos corpos das mulheres, sobre como são tecidos esses corpos-discursos. Não há como o modo de operação do poema, seu procedimento de escrita, ser separado da leitura.

\author{
A criação de redes entre mulheres \\ num útero cabem capelas \\ cabem bancos hóstias crucifixos \\ cabem padres de pau murcho \\ cabem freiras de seios quietos \\ cabem as senhoras católicas \\ que não usam contraceptivos \\ cabem as senhoras católicas \\ militando diante das clínicas \\ às $6 \mathrm{~h}$ na cidade do méxico \\ (FREITAS, 2012, p. 61).
}

Voltemos à matéria de Adelaide Ivánova no Suplemento Pernambuco. O segundo mote para a escrita do livro, conforme registra Adelaide, se deu quando Angélica Freitas acompanhou uma amiga em uma clínica de aborto no México e presenciou um protesto de mulheres religiosas.

4 Para Judith Butler em Bodies that Matter (1993), assim como Preciado (2014) faz referência, o sexo/gênero se constrói sob uma norma regulatória que se estabelece de forma reiterativa (repetição) e citacional (mantendo redes interdiscursivas). 
O desejo investigativo - a pauta de Um útero, digamos assim - nasceu de duas confrontações, nas quais, ao que me parece, Angélica parece ter sido (re)lembrada das especificidades de se viver como mulher. A primeira faísca veio da convivência com um coletivo feminista em Bahia Blanca, na Argentina. Ela se mudou pra lá porque se apaixonou por uma argentina (e como amamos pessoas capazes de mexer os próprios mundos e os próprios fundos em nome do amor!) e conta que, até ir lá, ninguém antes na vida dela era feminista, que a convivência com esse coletivo a fez questionar nossa linguagem e nossa conduta, como mulheres, e as coisas que a gente tem que relevar para viver em sociedade. (...) A segunda faísca veio algum tempo depois, quando, já morando na Holanda (para onde ela se mudou mais uma vez por causa da namorada - aleluia!), Angélica recebe uma ligação da melhor amiga dizendo "tô grávida, tô no México, vou fazer um aborto, vem pra cá plmdds". Ela sai correndo de Amsterdã pra Cidade do México, pra acudir a amiga - e só duas amigas que viveram isso juntas sabem o que é. (...) Dessas vivências - e porque Angélica "queria escrever um livro que pensasse o que é ser mulher. Não havia esse livro. Eu queria ler um poema sobre aborto. Não havia esse poema" -, nasce o projeto de Um útero, escrito, no fim das contas, entre $2007 \mathrm{e}$ 2011 (IVÁNOVA, 2017).

A todo tempo, tanto na entrevista ao Estratégias Narrativas, como na resenha do Suplemento Pernambuco, são ressaltadas as vivências das escritoras, seus incômodos com questões de gênero e a convivência de Angélica Freitas com feministas na Argentina, insinuando como os atravessamentos vida-política-mundo-texto são motores dessas escritas. Assim, entra em questão o corpo. Os corpos das autoras, os corpos dos poemas, os corpos que se encenam nos poemas, os corpos dos leitores... Coloco, portanto, a mesma pergunta que fazem Aguilar e Cámara (2017). "De que modo os corpos atuam na literatura?". Que corpos entram em jogo na escrita e na leitura? Que políticas atravessam e fazem esses corpos? Como sustentar uma divisão literatura vs mundo em um texto cujo mote passa pelo corpo? Considerar um livro como uma máquina performática torna tais perguntas inevitáveis. Como já comentava Paul Zumthor, em Performance, recepção e leitura, a introdução de um corpo vivo nos estudos literários "coloca tanto um problema de método como de elocução crítica" (ZUMTHOR, 2018, p. 27). Isto é, a partir dessas perguntas, o método de crítica passa a ser repensado. 
O escrito de Ivánova sobre o Útero é perpassado por seus sentimentos e impressões de quando o leu pela primeira vez e de como a impactou. "Não é que eu gostasse "muito" das coisas que ela faz. Era - e é - mais que isso: as coisas que eu mesma faço só existem porque Angélica fez as dela." (IVÁNOVA, 2017). Adelaide, portanto, decide como método de construção de sua resenha mapear essa influência também em outras escritoras. Ivánova continua "Pedi para 25 poetas vivas (nem todas puderam responder) me mandarem um pequeno relato sobre sua relação com Um útero.". Aparecem comentários de poetas como, por exemplo, Carla Diacov, Jarid Arraes e Julia Raiz enfatizando o papel do livro de Angélica na formação desta rede de poetas mulheres que tem impulsionado a cena atual da poesia no Brasil. Num desses trechos, Carla Diacov diz: "Um útero é do tamanho de um punho alimenta minhas tantas reentradas nesse mundo. O livro está em constante diálogo com minhas mulheres. É bonito o rebuliço.".

Perseguindo esta linha de reverberações, chegaremos ao Mugido ou diários de uma doula (2017) de Marília Flôor Kosby, com poemas que tratam, sobretudo, de experiências com partos de vacas e outros procedimentos veterinários. Ao final do livro se encontra um poema-anotação escrito por Angélica Freitas como um tipo de pósfácio. Em um dos poemas presentes no livro de Kosby o sujeito do poema se endereça a uma Angélica.

angélica,

o parto de uma vaca

não é uma coisa

simples

envolve um útero

imenso

que rebenta

e frequenta não raro

o lado de fora

[...]

o parto de uma vaca

requer punhos

firmes

finos porém

(KOSBY, 2017, p. 29). 
Não se trata de pressupor ou determinar que a "angélica" citada no poema é Angélica Freitas, mas, sobretudo, perceber as relações que se dão entre útero e punho mencionadas no poema de Marília Kosby ("envolve um útero/ imenso", "requer punhos/ firmes") e seus pontos de contato com Um útero é do tamanho de um punho (2012). O uso da letra minúscula e a falta de sobrenome dão um tom corriqueiro que inscreve esse vocativo ("angélica,") não como uma referência - embora possamos ler um diálogo com Angélica Freitas -, mas como um endereçamento. A estratégia do endereçamento presente em toda a história da literatura parece se direcionar para como "o poema se escreve com o outro, indo em direção a ele, endereçado, na medida em que há algo na composição que permite um trânsito entre o eu e o outro, para além das identificações identitárias." (CÁMARA et al., 2018, p. 117). Dessa maneira, não determinando o significante de "angélica", o poema propõe múltiplas interpretações do sujeito do poema se afastando de uma significação autoritária e identitária.

Ressalto o endereçamento no poema de Kosby porque este parece ter muito a dizer sobre o funcionamento dessa poesia (de Kosby, de Ivánova, de Freitas e de muitas outras mulheres poetas brasileiras) que, embora não pretenda fixar identidades, dá verdadeiros indícios de com quem o diálogo está sendo travado. Nas discussões sobre endereçamento presentes no Indicionário do contemporâneo, os autores citam a poesia de Ana Cristina César como exemplo para argumentar que "essa poesia evidencia o endereçamento como um modo de problematizar as leituras que postularam a intransitividade da palavra poética e sua autorreflexividade tais como as de Roman Jakobson ou do Formalismo Russo" (CÁMARA et al., 2018, p. 98), o que, de algum modo, apontaria para o gesto político do poema e sua participação no mundo. O aceno entre essas poetas mulheres aqui citadas, seja em sua produção crítica, seja no conteúdo dos poemas, indica uma literatura preocupada com formas de agrupamento e redefinição de comunidades e tradições literárias. Há, nestas aproximações, a possibilidade de montagem de uma cena na qual estão inscritos diálogos literários, críticos e políticos, demonstrando, de algum modo, os impactos e modos de funcionamento da poesia. Com os poemas de Angélica e suas reverberações, tornam-se perceptíveis as micro e macropolíticas com e para as quais os textos se desenvolvem mantendo, ainda, a mesma lógica do Google: a criação de redes. 


\section{um útero e a política (noje)}

O mais recente caso envolvendo o livro de Angélica Freitas reforça a perspectiva de concebê-lo enquanto algo que está dentro do mundo, enquanto um corpo político. Em 2019, Um útero é do tamanho de um punho foi alvo de uma moção de repúdio por parte de deputados conservadores do PSL e do PSC ao ser indicado como bibliografia obrigatória do vestibular de 2020 da UFSC e UFFS, segundo vídeo que viralizou em redes sociais e matérias de jornais digitais. De acordo com o Nexo Jornal, um dos deputados do PSL teria lido poemas do livro para outros deputados presentes em um pronunciamento. O deputado ganhou apoio de outros parlamentares conservadores ao defender que os alunos precisam de qualidade no ensino e de conteúdos que levariam para a vida, coisas que textos como este não cumpririam. É evidente que a falta de "qualidade" dos poemas, como sugere o deputado, é demonstrada por um léxico que demarcaria uma determinada posição política, contrária à dele. Os poemas - embora não possamos afirmar que possuam um tom reivindicativo por eles mesmos - apresentam conteúdos carregados de símbolos das lutas feministas. Eles não deixam dúvidas de seu vínculo com o mundo, com a política, com o corpo. Observase com isso que os poemas não são possíveis senão por suas relações com o mundo ou mesmo por fazerem mundo. O livro faz política. O livro não é, ele faz, ele se constitui como uma prática.

É importante lembrar, ainda, que Um útero é do tamanho de um punho (2012) foi patrocinado por um edital público da Petrobras de incentivo à arte e à cultura. Foi financiado, portanto, por uma política pública, pelo envolvimento do Estado e suas parcerias no fomento da cultura. Foi considerado, dentro dos critérios do edital, algo cabível de ser patrocinado naquele momento, nos fazendo pensar se o mesmo teria ocorrido nos dias de hoje. O livro agora recebe moção de repúdio por parte da mesma estrutura estatal, colocando em debate o conceito de literatura - e suas relativizações históricas e sociais -, a noção de uma literatura autônoma, desvinculada da circulação de mercadoria e do capital, e a figura do autor.

Para Walter Benjamin (2017), em seu ensaio "O autor como produtor", o escritor não é só parte do processo produtivo, mas também capaz de manter ou transformar os modos de produção literárias. Nesse sentido, o trabalho da crítica seria, para ele, o de refletir sobre qual o lugar do escritor nesse modo de produção. Benjamin declara que 
Assim, antes de perguntar qual é a posição de uma obra literária perante as relações de produção da época, gostaria de perguntar qual é sua posição dentro delas? Essa pergunta visa diretamente a função que a obra literária assume no âmbito das relações de produção literárias de uma época. Visa, por outras palavras, diretamente a técnica literária das obras (BENJAMIN, 2017, p. 85).

Nesse ensaio, segundo o teórico, o escritor pode alterar, através da técnica, os modos de produção literária. O que se parece sugerir é que, mais do que intervir nas relações literárias, o autor é capaz de alterar modos de agir e práticas sociais, ou seja, é capaz de alterar a vida. Assim, ler a figura do autor como parte do texto, junto dessa máquina performática, faz parte de uma descompartimentação da análise literária (que costuma separar autor versus texto versus história versus política...) e permite compreender como tudo que está envolvido em um texto impacta a sociedade. A descompartimentação do autor e do próprio texto, a retirada destes como entidades com barreiras rígidas, vai na contramão dos modos de produção capitalista, em que se aposta na divisão do trabalho e se propõe disciplinas e categorias estanques e específicas. Com a consideração dos múltiplos signos e corpos operando no texto, são propostas outras relações entre vida e obra e, sobretudo, outras relações de poder.

Nesse sentido, entende-se a literatura e as artes, em geral, como parte destas redes que estão sempre se dando, sem bordas fixas e bem delimitadas. A técnica utilizada por Angélica Freitas, uma técnica de reuso, de subversão de utilidade esperada coloca em jogo a própria poesia como um modo de usar. Isto é, propondo-se a retirada do poético de uma instituição estanque, de uma disciplina, e declarando-o em seus múltiplos usos, em uma práxis, que evidencia o poema e a crítica em seu caráter tecnológico, em seus processos de montagem e desmontagem, em suas diferentes possibilidades de ler, não dissociado ou autônomo em relação à sociedade do trabalho, da técnica, da construção do gênero ou da Internet.

\section{consideracões finais}

O que está em jogo é como o processo de escrita dos poemas, a partir de uma inquietação de Angélica Freitas, transformou-os em um dispositivo em si mesmo inquietador, capaz de impactar, de alguma maneira, a poesia feita 
por mulheres no Brasil e de pôr em debate a noção de poesia e seus modos de fazer ou de usar. O procedimento da googlagem, usado nos "3 poemas com auxílio do google", funciona como um método de investigação que poderia servir para observar as construções de diversas outras concepções da nossa sociedade e do nosso cotidiano. Além disso, retira a figura do autor de uma centralidade muito comum à história literária, de quem tem o dom ou a inspiração de criar algo "original". A autora - essa palavra de luxo - é uma usuária aleatória do Google. Esses aspectos demonstram como a produção do poema e tudo que o envolve está imbricado em sua leitura, desde as inquietações primeiras até as mais variadas reações a ele no mundo. Fazem parte, portanto, de um modo de ler e, logo, de fazer crítica.

O exercício elaborado através deste artigo foi o de ler um livro e um poema não só por eles mesmos, mas também na Internet, nos jornais, nas redes sociais e outras plataformas. Foi um exercício de procurar os desdobramentos de uma produção escrita no mundo e de tentar observar as faíscas entre texto e mundo e de como se tocam ao mesmo tempo, sem permitir barreiras. Um gesto que nos faz perceber como Um útero é do tamanho de um punho (2012) sugere tanto um outro uso do google, como da poesia e como a crítica de Ivánova mapeia os usos desse livro na poesia de mulheres brasileiras tal qual a dela própria.

Enquanto se observa, de maneira um tanto desordenada, a rede de signos entrelaçados no que se chama de poema ou de literatura, o que se encontra é, antes de mais nada, o potencial interventivo e criador de mundos da escrita ou, como dizem Deleuze e Guattari (1996), de cartografar "regiões por vir". Falo aqui de Um útero é do tamanho de um punho (2012) como uma máquina, pois é mediada por relações tecnológicas (de construção, discurso, técnica, montagem), performática, pois cria cenas e mundos, pois é uma prática, um ato.

Em resumo, a consequência de um modo de leitura e de crítica atrelado à noção de prática, de uso e, portanto, avesso à dinâmica compartimentadora do capitalismo, parece ser a do esgarçamento não apenas do texto, mas da própria noção de literário ou poético. A atividade de crítica de repensar o poema em seu além-grafismo, na multiplicidade de signos que são agenciados em um texto, parece exigir a consideração não mais de um poema, mas de um dispositivo que faz mundo, que faz corpo e que monta cenas. Põe-se em jogo a performatividade dos textos e seus usos, as 
identidades que criam e fixam, e corpos e discursos que estratificam ou desestratificam. Um modo de leitura desierarquizado não permite uma postura de poder vinda do grafismo ou de outras categorias (autor, obra, estética, etc). Tem-se, a todo tempo, uma oportunidade de se ler ou de se usar um texto de outra maneira, de virar do avesso escrituras hegemônicas do que é literatura, do que é um autor, do que é uma mulher.

\section{referências}

AGUILAR, Gonzalo; CÁMARA, Mario. A máquina performática: a literatura no campo experimental. Tradução: Gênese Andrade. Rio de Janeiro: Rocco, 2017.

AUSTIN, John Langshaw. Quando Dizer é Fazer: palavras e ação. Tradução: Danilo Marcondes de Souza Filho. Porto Alegre: Artes Médicas, 1990.

BAKHTIN, M. Estética da criação verbal. Tradução: Maria Ermantina Galvão; rev. trad. Marina Appenzeller. 3.ed. São Paulo: Martins Fontes, 2000.

BENJAMIN, Walter. "O autor como produtor". In: Estética e sociologia da arte. Edição e tradução João Barrento. Belo Horizonte: Autêntica Editora, 2017.

BRIN, Sergey; PAGE, Lawrence. "The anatomy of a large-scale hyper textual Web search engine". In: Computer networks and ISDN systems, vol. 30, p. 107-117, published by Elsevier Science B. V., 1998.

BUTLER, Judith. Bodies that matter: on the discursive limits of "sex". New York: Routledge, 1993.

CÁMARA, Mario; KLINGER, Diana; PEDROSA, Celia; WOLFF, Jorge (org.). Indicionário do contemporâneo. Belo Horizonte: UFMG, 2018.

DELEUZE, Gilles; GUATTARI, Félix. Mil platôs. vol. 1. São Paulo: Editora34, 1996.

ESTRATÉGIAS NARRATIVAS. Angélica Freitas, suas publicações e o feminismo. 2017. Disponível em: <https://www.youtube.com/ watch?v=DDgloKrGbrEs > Último acesso em: 14 de julho de 2018. 
. As influências e as alegrias da escrita. 2017. Disponível em: $<$ https:/l www.youtube.com/watch? $v_{=3} V_{1} 6 R 6 w f x S_{4} \& t=88 s>$. Último acesso em: 14 de julho de 2018.

FREITAS, Angélica. Um útero é do tamanho de um punho. São Paulo: Cosac Naify, 2012.

. "A mulher é: uma googlagem". In: Elyra, Revista da Rede Internacional Lyracompoetics, vol. 7, 2016. Disponível em: <https://www.elyra.org/index. php/elyra/article/view/130>. Último acesso em: 17 de janeiro de 2020.

IVÁNOVA, Adelaide. "Como age, pensa e o que é uma mulher?". In: Suplemento Pernambuco. Ed. 139. Setembro, 2017. Disponível em: <https:/l suplementopernambuco.com.br/edi\% $\mathrm{C}_{3} \% \mathrm{~A} 7 \% \mathrm{C}_{3} \% \mathrm{~B} 5$ es-anteriores/77capa/1943-como-age,-pensa-e-o-que-\% $\% C_{3} \%$ Ag-uma-mulher.html>. Último acesso em: 17 de janeiro de 2020.

KOSBY, Marília Floôr. Mugido ou diários de uma doula. $1^{\text {a }}$ edição. Rio de Janeiro: edições garupa, 2017.

KRAUSS, Rosalind. "A Escultura no Campo Ampliado". In: Gávea, nº 1 , Rio de Janeiro: PUC, 1984.

LIMA, Juliana Domingos de. "O livro que deputados querem tirar do vestibular da UFSC". In: Nexo. 23 de set de 2019. Disponível em: <https://www. nexojornal.com.br/expresso/2019/og/23/O-livro-que-deputados-queremtirar-do-vestibular-da-UFSC>. Último acesso em: 17 de janeiro de 2020.

PRECIADO, Paul Beatriz. Manifesto contrassexual: práticas subversivas de identidade sexual. Tradução de Maria Paula Gurgel Ribeiro. São Paulo: N-1 edições, 2014 .

ZUMTHOR, Paul. Performance, Recepção, Leitura. Tradução de Jerusa Pires Ferreira e Suely Fenerich. São Paulo: Ubu, 2018.

Artigo recebido em: 19/01/2020

Aceito em: 24/06/2020 